\title{
Spectrophotometric Studies of Lamotrigine Charge Transfer Complexes: Synthesis and Characterization
}

\author{
Najma Sultana ${ }^{1 *}$, Saeed Arayne $\mathrm{M}^{2}$ and Saeeda Nadir $\mathrm{Ali}^{2}$ \\ ${ }^{1}$ Research Institute of Pharmaceutical Sciences, Faculty of Pharmacy, University of Karachi, Karachi-75270, Pakistan \\ ${ }^{2}$ Department of Chemistry, University of Karachi, Karachi-75270, Pakistan
}

\begin{abstract}
Charge transfer complexes of lamotrigine with 7,7,8,8-tetracyanoquinodimethane, bromothymol blue and picric acid have been investigated by spectrophotometric method. Optimum conditions for the reactions and validation data is reported. Resulting complexes absorb at 394, 404 and $374 \mathrm{~nm}$ in the Beer's law range of 0.15-15, 0.2510 and $3.0-18 \mu \mathrm{g} \mathrm{mL}^{-1}$ with correlation coefficient greater than 0.998 in each case and detection limits 45,47 and $57 \mu \mathrm{g} \mathrm{mL}-1$ respectively. The data are discussed in terms of molar absorptivity, association constant and Gibb's free energy. Spectral characteristics including oscillator's strength, dipole moment, ionization potential, energy of complexes and resonance energy have been determined. Benesi-Hildebrand plots for each complex have been constructed. The proposed method was applied successfully for the determination of lamotrigine in pharmaceutical formulations. Satisfactory recovery values suggested that the method is reliable for the determination of lamotrigine in pharmaceutical formulations without interference of excipients. Further, solid charge transfer complexes were synthesized and characterized by IR and ${ }^{1} \mathrm{H}$ NMR spectroscopy.
\end{abstract}

Keywords: Charge transfer complexes; Lamotrigine; $\pi$ acceptors; Dye stuffs; Benesi-Hildebrand plot

\section{Introduction}

Lamotrigine (LAM) is an anticonvulsant drug; belong to drug class of phenyltriazine. It is used to treat epilepsy, bipolar disorder and neurological lesions and also act as a tranquilizer [1,2]. Like other anticonvulsant, it also behaves as an effective mood stabilizer. Chemically it is 6-(2,3-dichlorophenyl)-1,2,4-triazine-3,5-diamine and its structural formula is given in Figure 1.

Many of the methods have been reported for the determination of LAM including HPLC and GC [3], capillary electrophoresis [4], titrimetry [5] and voltammetry [6]. Literature survey revealed a number of spectrophotometric methods for the determination of LAM [7] in acidic medium [8], in basic medium [9], through CT and ion pair complexes with bromophenol blue [10], bromocresol green [11], bromocresol purple [12], chlorophenol red [13], p-chloranilic acid [14], through oxidation of LAM [15].

Analysis of drugs employing spectrophotometric method is being carried out in our laboratory for few years. Methods for the determination of verapamil [16], gabapentin [17], quinolone

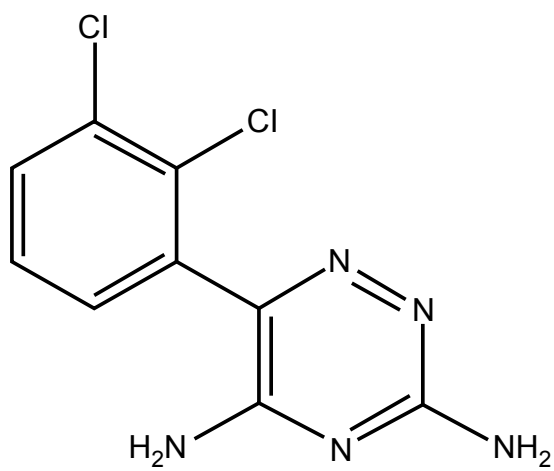

Figure 1: Structure of LAM. antibiotics [18], metformin [19], ascorbic acid [20] and montelukast [21] have been developed spectrophotometrically by our research fellows. Currently, we are working on charge transfer complexes of gabapentin, ibuprofen, omeprazole and few other bulk drugs. In continuation of our work, this paper describes sensitive and rapid spectrophotometric method for the determination of LAM through charge transfer complexes with TCNQ, BTB and PA utilizing low cost easily available solvent. The method is simple and reports many of spectral characteristics including oscillator's strength, dipole moment, ionization potential, energy of complexes, resonance energy and also the thermodynamic parameters i.e. association constant and Gibb's free energy changes which have never been determined in previously reported methods. Benesi-Hildebrand plots for each complex have been constructed. Further, solid CT complexes of LAM were synthesized and characterized by IR and ${ }^{1} \mathrm{H}$ NMR spectroscopy. Moreover, the developed methods have been successfully applied for the determination of LAM in pharmaceutical formulation without interference of excipients.

\section{Experimental}

\section{Materials and reagents}

LAM was obtained from Searle Pakistan Ltd and Lamnet ${ }^{\circledR} 25 \mathrm{mg}$ was purchased from the local pharmacy. TCNQ and BTB were purchased from Merck (Darmstadt, Germany) and PA was purchased from Sigma

${ }^{*}$ Corresponding author: Najma Sultana, Research Institute of Pharmaceutical Sciences, Faculty of Pharmacy, University of Karachi, Karachi-75270, Pakistan, E-mail: araynezs@gmail.com

Received May 10, 2013; Accepted July 08, 2013; Published July 26, 2013

Citation: Sultana N, Saeed Arayne M, Ali SN (2013) Spectrophotometric Studies of Lamotrigine Charge Transfer Complexes: Synthesis and Characterization. Pharm Anal Acta 4: 260. doi:10.4172/2153-2435.1000260

Copyright: $\odot 2013$ Sultana N, et al. This is an open-access article distributed under the terms of the Creative Commons Attribution License, which permits unrestricted use, distribution, and reproduction in any medium, provided the original author and source are credited. 
Aldrich Chemie $\mathrm{GmbH}$. All the solvents used were of analytical grade and double distilled de-ionized water was used throughout the analysis.

\section{Apparatus}

Electronic spectra of LAM and its complex were recorded in the region 200-800 $\mathrm{nm}$ using Shimadzu 1800 double beam UV-visible spectrophotometer version 3.9 software with quartz cells of $1.0 \mathrm{~cm}$ path length. The IR spectra were obtained from $\mathrm{KBr}$ discs using Shimadzu Prestige-21200VEC version 1.2 software and ${ }^{1} \mathrm{H}$ NMR spectra were measured on Bruker AMX 500MHz spectrophotometer using TMS as internal standard and MeOD as solvent.

\section{Standard stock solutions}

- $0.39 \times 10^{-2} \mathrm{M}$ LAM in methanol

- $0.49 \times 10^{-2}$ TCNQ in methanol

- $0.16 \times 10^{-2} \mathrm{M} \mathrm{BTB}$ in double distilled deionized water

- $0.43 \times 10^{-2} \mathrm{M}$ PA in methanol

- Phthalate buffer of $\mathrm{pH}$ ranging from 2.2-4.0 was prepared by dissolving $20.4 \mathrm{~g}$ potassium hydrogen phthalate in $1.0 \mathrm{~L}$ distilled water and $\mathrm{pH}$ of solution was maintained by adding $0.1 \mathrm{M} \mathrm{HCl}$.

\section{General Procedure}

\section{Method for TCNQ and PA}

Aliquots of stock standard solution of LAM in the concentration range of $0.15-15$ and 3.0-18 $\mu \mathrm{gmL}^{-1}$ were transferred into two separate series of $10 \mathrm{ml}$ volumetric flasks; to each flask $1 \mathrm{~mL}$ of TCNQ and $1 \mathrm{~mL}$ of PA were added in the respective series. These solutions were allowed to react at room temperature for $15 \mathrm{~min}$. The volume was made up to the mark with methanol and the absorbance was measured against reagent blank treated similarly.

\section{Method for BTB}

LAM solution in the concentration range of $12-96 \mu \mathrm{gmL}^{-1}$ was transferred in to $10 \mathrm{~mL}$ volumetric flaks, to this $3.0 \mathrm{~mL}$ buffer of $\mathrm{pH} 3.4$ and $2.5 \mathrm{~mL}$ BTB solution was added and the volume was completed with distilled water. The mixture was then transferred into $50 \mathrm{~mL}$ separating funnel and extracted with $20 \mathrm{~mL}$ chloroform in two portions. The absorbance of extracted organic layer was measured against reagent blank treated similarly. The standard calibration graph was prepared by plotting absorbance vs. concentration of LAM.

\section{Pharmaceuticals formulation}

Twenty tablets of $25 \mathrm{mg}$ Lamnet $^{\circledR}$ were finely triturated. The powder equivalent to $100 \mathrm{mg}$ of LAM was dissolved in methanol and shaken well for proper mixing. This solution was allowed to stand for $30 \mathrm{~min}$ and then sonicated for complete solubilization of drugs. Then the contents were filtered to separate the insoluble excipients and volume was completed with same solvent to get the final concentration of $1000 \mu \mathrm{g} \mathrm{mL}^{-1}$. The procedure was continued as described under the procedure for pure LAM.

\section{Synthesis of solid CT Complexes}

Solid CT complexes were synthesized by refluxing the LAM with each of the complexing agent separately for 2 hrs in the ratio of $1: 1$ as found through the stoichiometric study by applying Job's method. The resulting product in each case was filtered off and washed with minimum amount of methanol. The excess solvent was evaporated to dryness. The solid CT complexes were characterized by UV-visible, IR and ${ }^{1} \mathrm{H}$ NMR spectroscopy.

\section{Results and Discussion}

LAM, being a nitrogenous drug is present in the positively charged protonated form. It is reported to form CT complexes with many of compounds. In the present study, efforts have been made to develop the complexes of LAM with TCNQ, BTB and PA. It was observed that LAM interact with all of these agents in the stoichiometric ratio of 1:1 as determined by applying Job's method of continuous variation [22] leading to the formation of bluish green, yellow and dark yellow CT complexes. In all resulting product, LAM is in positively charged protonated form, whereas TCNQ forms radical anion and sulfonephthalein group of BTB and hydroxyl group of PA form anion. The newly formed complexes show intense absorption bands at 394 , 404 and $374 \mathrm{~nm}$ respectively. The electronic absorption spectra of these complexes are given in Figure 2.

Different parameters influencing the intensity of absorption bands were investigated to establish the optimum experimental conditions for the assay. It was observed that the complete complexation occurs instantaneously for TCNQ and PA and absorbance remains constant for $24 \mathrm{hrs}$. The optimum reaction time for LAM-BTB complex was determined by investigating the absorbance of complex at every minute while shaking the reaction mixture. It is apparent from the Figure 3 that complete interaction occurs after proper shaking of mixture for $2 \mathrm{~min}$ and it also found to be stable for $24 \mathrm{hr}$. The effect of reagent concentration was examined by adding different volumes of $0.49 \times 10^{-2}$ $\mathrm{M}$ TCNQ, $0.16 \times 10^{-2} \mathrm{M}$ BTB and $0.43 \times 10^{-2} \mathrm{M}$ PA in to a fixed amount of LAM. The $1 \mathrm{~mL}$ TCNQ and PA and $2.6 \mathrm{~mL} \mathrm{BTB}$ were found to be appropriate for complete complexation. For BTB method, buffer of suitable $\mathrm{pH}$ was selected by testing them in the range of 2.0-4.0 and the maximum absorbance was obtained at $\mathrm{pH}$ 3.4. For proper extraction of complex, solvents like benzene, carbon tetra chloride, dichloromethane and chloroform were tested. Double extraction with chloroform was supposed to be adequate for maximum recovery.

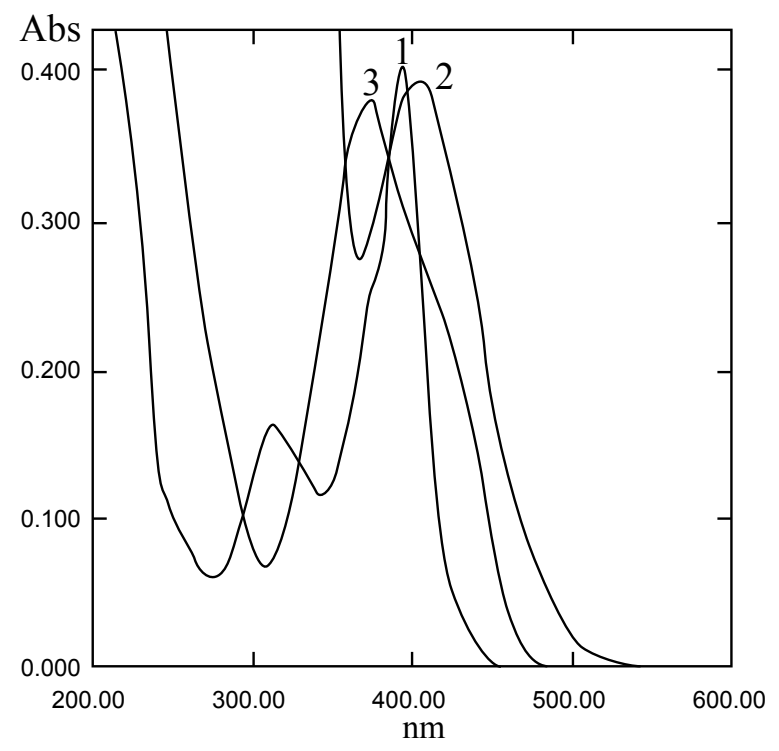

Figure 2: UV spectra of LAM complexes with (1) TCNQ, (2) BTB and (3) PA 


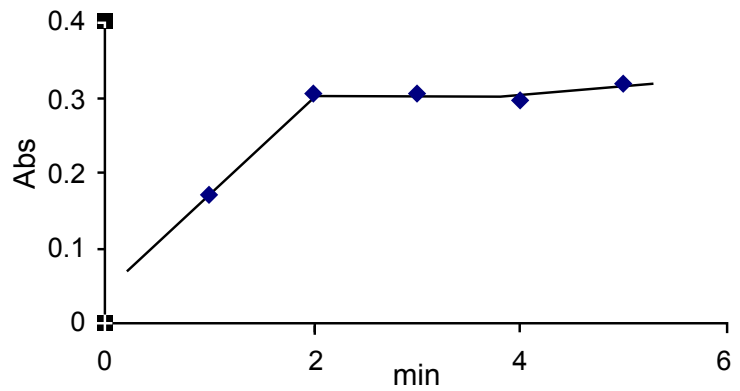

Figure 3: Effect of shaking time on LAM-BTB complex.

\section{Analytical data}

At the established experimental conditions, standard calibration curves for LAM with TCNQ, BTB and PA were constructed by plotting absorbance verses concentration. The linear regression curves were obtained in the Beer's law range of 0.15-15, 0.25-10 and 3.0-18 $\mu \mathrm{g} \mathrm{mL}^{-1}$ with correlation coefficient greater than 0.998 in each case respectively. Regression characteristics including slope, intercept, correlation coefficient and also the molar absorptivity values for each proposed method are given in Table 1. Limit of detection and quantitation were determined to establish the sensitivity of method. The LOD values were calculated to be 45,47 and $57 \mathrm{ng} \mathrm{mL}^{-1}$ respectively (Table 1). Reproducibility of the method was measured for a series of six determinations at six concentration level. The data of percent relative standard deviation obtained for each method are reported in Table 2. The \%RSD values in the range of $0.02-1.72,0.05-0.45$ and $0.31-1.28$ confirm the sensitivity of method.

\section{Pharmaceutical formulation}

The proposed method was successfully applied for the determination of LAM in its dosage formulation. Six determinations were made at three concentration levels. The results obtained are shown in Table 3. Satisfactory recovery data was obtained in the range of $98.93-100.88 \%, 99.75-99.78 \%$ and $99.54-100.88 \%$ for TCNQ, BTB and PA. The low percent error indicated the reliability of method. The assay results were in good agreement with the label claim. Also, the effect of commonly found excipients was determined by scanning the blank solution of LAM and the placebo solutions. The percent recovery values given in Table 4 indicate that excipients of tablet did not found to interfere during the assay.

\section{Spectral characteristics of CT complexes}

The experimental oscillator strength $(f)$ and transition dipole moment $(\mu)$ of newly formed CT complexes were determined by formulae given in equation (1) and (2) $[23,24]$;

$$
\begin{aligned}
& f=\left(4.319 \times 10^{-9}\right) \varepsilon_{\max } \cdot v_{1 / 2} \\
& \mu=0.0958\left(\varepsilon_{\max } \cdot v_{1 / 2} / v_{\max }\right)^{1 / 2}
\end{aligned}
$$

where $\varepsilon_{\max }$ is the molar extinction coefficient at maximum absorbance, $v_{1 / 2}$ is the band-width at half absorbance in $\mathrm{cm}^{-1}$ and $v_{\max }$ is wave number in $\mathrm{cm}^{-1}$. Relatively large values of oscillator strength indicate the strength of complexes. The ionization potential (Ip) of free donor was calculated by using the equation (3) [25],

$$
\mathrm{I}_{\mathrm{p}}=5.76+1.53 \times 10^{-4} v_{\mathrm{CT}}
$$

where $v_{\mathrm{CT}}$ is the wave number in $\mathrm{cm}^{-1}$ corresponding to the CT band of complex formed between donor and acceptor. The resonance energy of CT complex in the ground state was determined by Brieglab and Czekalla equation (4) given bellow [26]:

$$
\varepsilon_{\max }=7.7 \times 10^{-4} /\left[\mathrm{h} v_{\mathrm{CT}} / \mathrm{R}_{\mathrm{N}}-3.5\right]
$$

The energy of CT complexes was calculated by applying the relationship given in equation (5) [24]:

$$
\mathrm{E}_{\mathrm{CT}}=1243.667 / \lambda_{\mathrm{CT}}
$$

where $\lambda_{\mathrm{CT}}$ is the wavelength of CT band at maximum absorbance. All the spectral data including oscillator strength, dipole moment, ionization potential, resonance energy and energy of CT complexes are presented in Table 5.

The association constant was determined by employing BenesiHildebrand equation [27].

\begin{tabular}{|c|c|c|c|}
\hline Parameters & LAM-TCNQ & LAM-BTB & LAM-PA \\
\hline$\lambda_{\max }(\mathrm{nm})$ & 394 & 404 & 374 \\
\hline Linearity range $\mu \mathrm{gmL}^{-1}$ & $0.15-15$ & $0.25-10$ & $3.0-18$ \\
\hline Molar absorptivity & 12258 & 19643 & 7436 \\
\hline Slope & $3.56 \mathrm{E}-02$ & $4.90 \mathrm{E}-02$ & $2.43 \mathrm{E}-02$ \\
\hline Intercept & 0.0 .0633 & 0.2719 & 0.0857 \\
\hline Correlation coefficient & 0.9985 & 0.9986 & 0.9986 \\
\hline${\text { LOD } \text { ngmL }^{-1}}^{-1}$ & 0.045882 & 0.047621 & 0.057616 \\
\hline${\text { LOQ } \mu \mathrm{gmL}^{-1}}$ & 0.139038 & 0.144308 & 0.174594 \\
\hline
\end{tabular}

Table 1: Optimum conditions and analytical parameters.

\begin{tabular}{|c|c|c|c|c|c|}
\hline \multicolumn{2}{|c|}{ LAM-TCNQ } & \multicolumn{2}{c|}{ LAM-BTB } & \multicolumn{2}{c|}{ LAM-PA } \\
\hline Conc & \%RSD & Conc & \%RSD & Conc & $\%$ RSD \\
\hline 0.15 & 0.33 & 1 & 0.05 & 3 & 0.32 \\
\hline 3 & 1.72 & 2 & 0.18 & 6 & 0.61 \\
\hline 6 & 0.62 & 4 & 0.15 & 9 & 2.28 \\
\hline 9 & 0.14 & 6 & 0.18 & 12 & 0.31 \\
\hline 12 & 0.70 & 8 & 0.45 & 15 & 0.77 \\
\hline 15 & 0.02 & 10 & 0.24 & 18 & 1.27 \\
\hline
\end{tabular}

Table 2: Precision of method.

\begin{tabular}{|c|c|c|c|c|c|c|c|c|}
\hline \multicolumn{3}{|c|}{ LAM-TCNQ } & \multicolumn{3}{c|}{ LAM-BTB } & \multicolumn{3}{c|}{ LAM-PA } \\
\hline Conc & $\%$ Rec & $\%$ Err & Conc & $\%$ Rec & $\%$ Err & Conc & $\%$ Rec & $\%$ Err \\
\hline 3 & 100.47 & 0.46 & 2 & 99.75 & -0.25 & 3 & 100.88 & 0.87 \\
\hline 6 & 98.93 & -1.08 & 4 & 99.78 & -0.22 & 6 & 99.54 & -0.46 \\
\hline 9 & 100.88 & 0.87 & 6 & 99.75 & -0.25 & 9 & 100.87 & 0.86 \\
\hline \multicolumn{10}{|c|}{ Table 3: Accuracy of method. } \\
\hline
\end{tabular}

\begin{tabular}{|c|c|c|c|}
\hline \multirow{2}{*}{ Excipients } & LAM-TCNQ & \multicolumn{3}{|c|}{$\begin{array}{c}\text { LAM-BTB } \\
\text { \% Recovery }\end{array}$} \\
\cline { 2 - 4 } & \multicolumn{3}{|c|}{ LAM-PA } \\
\hline Pyrrolidone & 99.13 & 99.76 & 99.86 \\
\hline Lactose & 98.61 & 100.22 & 100.30 \\
\hline Talc & 100.40 & 99.29 & 100.46 \\
\hline $\begin{array}{c}\text { Magnesium } \\
\text { stearate }\end{array}$ & 100.17 & 99.68 & 98.97 \\
\hline Starch & 99.58 & 101.42 & 100.89 \\
\hline
\end{tabular}

Table 4: Recovery of lamotrigine in presence of different excipients.

\begin{tabular}{|c|c|c|c|c|c|c|c|}
\hline Complex & $\mathrm{f}$ & $\mu$ & $\mathrm{Ip}$ & $\mathrm{E}_{\mathrm{CT}}$ & $\mathrm{R}_{\mathrm{N}}$ & $\begin{array}{c}\mathrm{Kc} \times 10^{2} \\
(\text { lit/mol) }\end{array}$ & $\begin{array}{c}\Delta \mathrm{G}^{\circ} \\
(\mathrm{KCal})\end{array}$ \\
\hline LAM-TCNQ & 12.31 & 32.11 & 9.64 & 3.16 & 0.90 & 2.06 & 3.15 \\
\hline LAM-BTB & 9.53 & 28.61 & 9.55 & 3.08 & 0.88 & 9.56 & 4.06 \\
\hline LAm-PA & 3.45 & 16.57 & 9.85 & 3.33 & 0.95 & 3.26 & 3.42 \\
\hline
\end{tabular}

Table 5: Spectrophotometric results. 
Citation: Sultana N, Saeed Arayne M, Ali SN (2013) Spectrophotometric Studies of Lamotrigine Charge Transfer Complexes: Synthesis and Characterization. Pharm Anal Acta 4: 260. doi:10.4172/2153-2435.1000260

Page 4 of 6

$$
\left[\mathrm{A}_{\mathrm{o}}\right] / \mathrm{A}=1 / \mathrm{K}\left[\mathrm{D}_{\mathrm{o}}\right] . \varepsilon+1 / \varepsilon
$$

where, $\mathrm{K}$ is the association constant, $\mathrm{A}$ is absorbance, $\varepsilon$ is molar extinction coefficient and $\left[A_{0}\right]$ and $\left[D_{0}\right]$ are the initial concentrations of the acceptor and donor respectively. The values for Kc are given in Table 5. Further investigation was made by plotting the values of $1 / \mathrm{D}_{0}$ versus $\mathrm{A}_{0} / \mathrm{A}$, which showed linear curve in all the cases. Table 6 presents the values and the graphs are displayed in Figure 4.

The standard free energy changes $\left(\Delta \mathrm{G}^{\circ}\right)$ associated with GBP complexation reactions were calculated from the association constants by applying equation (2) [28]. The values of $\Delta \mathrm{G}^{\circ}$ for each complex are given in Table 5.

$$
\Delta \mathrm{G}^{\circ}=-2.303 \mathrm{RT} \log \mathrm{K}_{\mathrm{C}}
$$

where, $\Delta \mathrm{G}^{\circ}$ is the free energy change of the complex in $\mathrm{KJ} \mathrm{mol}^{-1}$, $\mathrm{R}$ is the gas constant $\left(1.987 \mathrm{cal} \mathrm{mol}^{-1} \mathrm{deg}^{-1}\right)$, $\mathrm{T}$ is temperature in Kelvin and $\mathrm{K}_{\mathrm{c}}$ is the association constant of drug-acceptor complexes.

\section{Spectroscopic study}

Spectroscopic studies of free donor and formed complexes were carried out to determine the structure of complexes. The IR spectra (Figure 5) were recorded using $\mathrm{KBr}$ discs and ${ }^{1} \mathrm{H}$ NMR spectra were measured at room temperature in MeOD. The IR spectra of LAM shows characteristic peak of $-\mathrm{NH}_{2}$ at $3350 \mathrm{~cm}^{-1}$ which shift to 3450 , 3448 and $3215 \mathrm{~cm}^{-1}$ in LAM complexes with TCNQ, BTB and PA respectively, confirming that the interaction has occurred at $-\mathrm{NH}_{2}$ site. The infrared frequencies and band assignments are given in Table 7 and the chemical shift values for the detected peaks are mentioned in Table 8. On the basis of spectroscopic data, the proposed chemical structure of LAM complexes with TCNQ, BTB and PA are given in Figure 6.

\section{Advantages over reported methods}

For the determination of LAM several techniques have been applied. A number of articles have been published for its determination in bulk drug, commercial formulations, biological and clinical samples. Recently, different reported spectrophotometric methods have been compared by vinay et al. [8] with their reported methods. Almost all of the previously reported methods are relatively less sensitive, time consuming or require the expensive reagents. In comparison, present study describe simple and more sensitive UV/ visible method based on the formation of charge transfer complexes of LAM with easily available reagents like TCNQ, BTB and PA. Simple methodology is

\begin{tabular}{|l|l|l|l|l|l|}
\hline Complex & $\mathrm{D}(\mathrm{M}) \times 10^{-3}$ & $\mathrm{~A}(\mathrm{M}) \times 10^{-3}$ & $\mathrm{Abs}$ & $1 / \mathrm{D} \times 10^{5}$ & $\mathrm{~A} / \mathrm{Abs} \times 10^{-2}$ \\
\hline \multirow{5}{*}{ LAM-TCNQ } & 0.023 & 4.90 & 0.2867 & 0.43 & 1.71 \\
\cline { 2 - 6 } & 0.035 & 4.90 & 0.4033 & 0.28 & 1.22 \\
\cline { 2 - 6 } & 0.047 & 4.90 & 0.4886 & 0.21 & 1.00 \\
\hline & 0.059 & 4.90 & 0.5868 & 0.17 & 0.84 \\
\hline \multirow{3}{*}{ LAM-BTB } & 0.070 & 4.90 & 0.8619 & 0.14 & 0.57 \\
\hline & 0.008 & 1.60 & 0.3932 & 1.28 & 0.41 \\
\cline { 2 - 6 } & 0.016 & 1.60 & 0.4633 & 0.64 & 0.35 \\
\hline & 0.023 & 1.60 & 0.5574 & 0.43 & 0.29 \\
\hline \multirow{5}{*}{ LAM-PA } & 0.031 & 1.60 & 0.6065 & 0.32 & 0.26 \\
\hline & 0.039 & 1.60 & 0.7673 & 0.26 & 0.21 \\
\hline & 0.012 & 3.06 & 0.298 & 0.85 & 1.03 \\
\hline & 0.047 & 3.06 & 0.381 & 0.21 & 0.80 \\
\hline & 0.070 & 3.06 & 0.466 & 0.14 & 0.66 \\
\hline & 0.094 & 3.06 & 0.675 & 0.11 & 0.45 \\
\hline
\end{tabular}

Table 6: The values of $\left[A_{0}\right] / A b s$ and $1 /\left[D_{0}\right]$ for lamotrigine complexes.

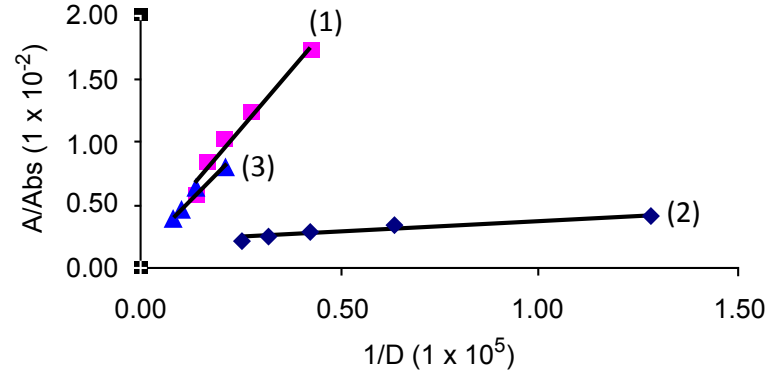

Figure 4: BH plot for LAM complexes with (1) TCNQ, (2) BTB and (3) PA

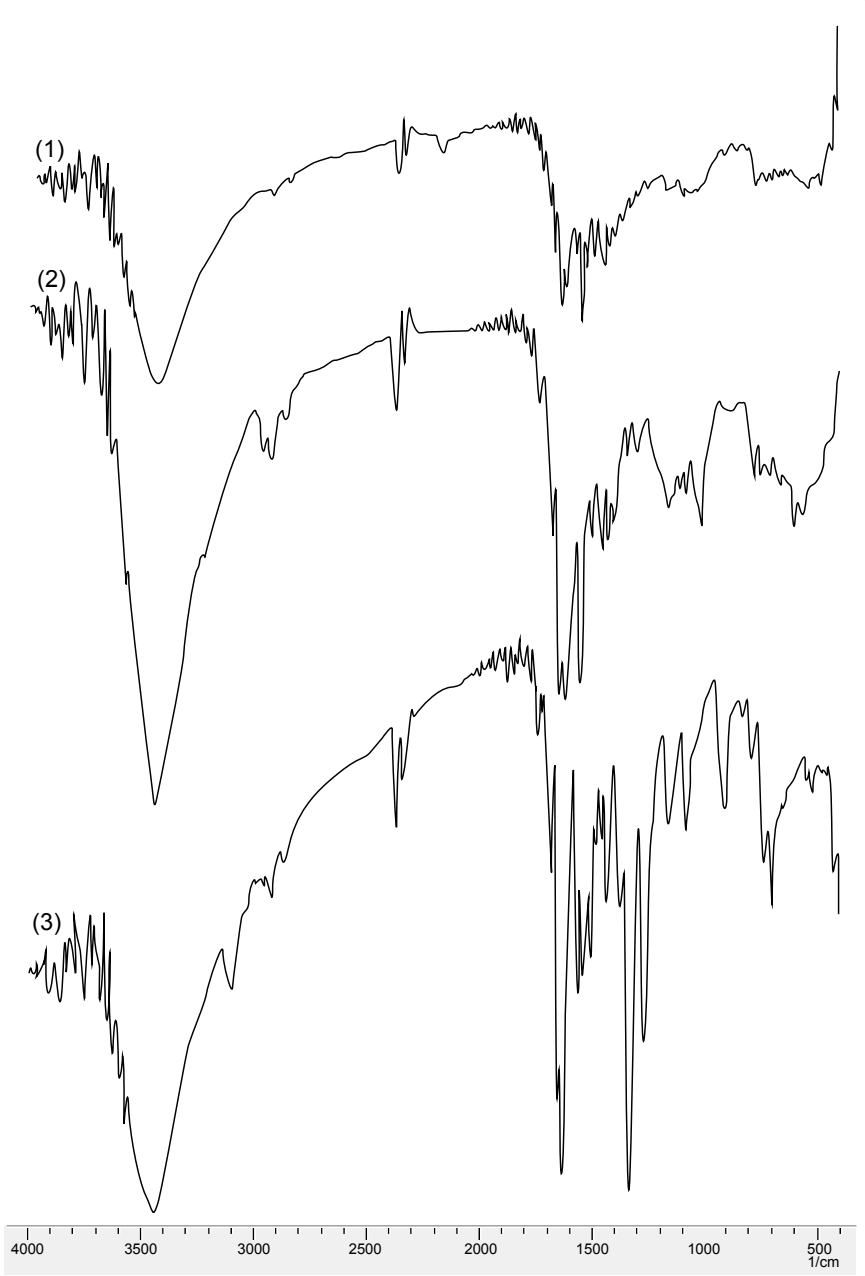

Figure 5: IR spectra of LAM complexes with (1) TCNQ, (2) BTB and (3) PA.

applied and results are calculated without employing any complicated equations. Moreover, none of the reported methods explicate the spectral characters of LAM and its complexes. Here, we reported the oscillator's strength, dipole moment, ionization potential, energy of complexes, resonance energy, association constant and Gibb's free energy changes and constructed the Benesi-Hildebrand plot in each case. The interday and intraday precision and percent recovery values were evaluated. Results of analysis were validated successfully. These methods were successfully applied for the determination of LAM in 
Citation: Sultana N, Saeed Arayne M, Ali SN (2013) Spectrophotometric Studies of Lamotrigine Charge Transfer Complexes: Synthesis and Characterization. Pharm Anal Acta 4: 260. doi:10.4172/2153-2435.1000260

Page 5 of 6

\begin{tabular}{|c|c|c|c|c|}
\hline LAM & LAM-TCNQ & LAM-BTB & LAM-PA & Assignment \\
\hline 3350 & 3450 & 3448 & 3215,3856 & $\mathrm{v}(\mathrm{N}-\mathrm{H})$ \\
\hline 2954,2850 & 2924,2858 & 2924 & 2924 & $\mathrm{v}(\mathrm{C}-\mathrm{H})$ \\
\hline- & - & - & 1653,1683 & $\mathrm{v}\left(\mathrm{NO}_{2}\right)$ \\
\hline 1560 & 1560 & 1558 & 1583 & $\mathrm{v}(\mathrm{C}=\mathrm{N})$ \\
\hline 1541 & 1541 & 1541 & 1546 & $\mathrm{v}(\mathrm{C}=\mathrm{C})$ \\
\hline 1502 & - & 1506 & 1506 & $\mathrm{v}(\mathrm{N}-\mathrm{H})$ \\
\hline 1440 & 1462,1440 & 1460 & 1460 & $\mathrm{v}(\mathrm{C}-\mathrm{H})$ deformation \\
\hline 1327 & 1346 & 1300 & 1328 & $\mathrm{v}(\mathrm{C}-\mathrm{N})$ \\
\hline 1382 & - & 1342 & 1382 & $\mathrm{v}(\mathrm{C}-\mathrm{C})$ \\
\hline- & 1174 & 1172 & 1237 & $\mathrm{v}(\mathrm{C}-\mathrm{O})$ \\
\hline 1157 & 1163 & 1163 & 1159 & $\mathrm{v}(\mathrm{C}-\mathrm{H})$ in $\mathrm{plane}$ \\
\hline- & - & - & 1035 & $\mathrm{v}\left(\mathrm{NO}_{2}\right)$ \\
\hline- & - & 1018 & - & $\mathrm{v}(\mathrm{S}=\mathrm{O})$ \\
\hline 846 & 842 & 853 & 846 & $\delta_{\text {rock }} \mathrm{CH}_{2}$ \\
\hline- & - & 613 & - & $\mathrm{v}(\mathrm{S}-\mathrm{O})$ \\
\hline
\end{tabular}

Table 7: Infrared frequencies and their assignments.

\begin{tabular}{|c|c|c|c|c|}
\hline Assignment & LAM & LAM-TCNQ & LAM-BTB & LAM-PA \\
\hline$\left(\mathrm{s}, \mathrm{NH}_{2}\right)$ & $\delta 4.83$ & $\delta 4.56$ & $\delta 4.52$ & $\delta 4.56$ \\
\hline$(\mathrm{m}$, arayl $)$ & $\delta 7.34-7.66$ & $\delta 7.40-7.73$ & $\delta 6.94-7.67$ & $\delta 7.34-7.71$ \\
\hline$\left(\mathrm{d}, 4 \mathrm{CH}_{3}\right)$ & - & - & $\delta 0.991$ & - \\
\hline$\left(\mathrm{s}, \mathrm{CH}_{3}\right)$ & - & - & $\delta 1.99$ & - \\
\hline$\left(\mathrm{s}, \mathrm{CH}_{3}\right)$ & - & - & $\delta 2.13$ & - \\
\hline$(\mathrm{m}, 2 \mathrm{CH})$ & - & - & $\delta 3.29$ & - \\
\hline
\end{tabular}

Table 8: ${ }^{1} \mathrm{H}$ NMR spectra.<smiles>CC(C)C1=CCC(C(=[W])C#N)=CC1</smiles>

(1)<smiles>Nc1nc([NH3+])nnc1-c1cccc(Cl)c1[N+](=O)[O-]</smiles><smiles>CC(C)C1=CC(=C(c2ccccc2C(C)C)c2ccccc2S(=O)(=O)O[SnH2]c2nnc(-c3cccc(Cl)c3Cl)c(N)n2)C=C(Br)C1=O</smiles>

(2)

Figure 6: Proposed structure of LAM complexes with (1) TCNQ, (2) BTB and (3) PA.

pharmaceutical formulations. Commonly present excipients did not show interference during analysis. Solid charge transfer complexes were synthesized and characterized by IR and ${ }^{1} \mathrm{H}$ NMR spectroscopy.

\section{Conclusion}

The aim of present study was

- Development of charge transfer complexes of LAM with TCNQ, BTB and PA.

- Application of developed complexes for the UVspectrophotometric determination of LAM in bulk and its formulation.

The investigation comprised the determination of its spectral characteristics including oscillator's strength, dipole moment, ionization potential, energy of complexes, resonance energy, association constant and Gibb's free energy changes. Benesi-Hildebrand plots for each complex have been constructed. Also, the solid CT complexes were synthesized and characterized by IR and ${ }^{1} \mathrm{H}-\mathrm{NMR}$ spectroscopy. Further, LAM was determined in bulk and its formulation by means of charge transfer complexes. Calibration graphs plotted between absorbance verses concentration of LAM were found to be linear within the limit of Beer's law with correlation coefficient greater than 0.998. The assay results were in good agreement with the label claim. Commonly present excipients did not found to interfere during the assay.

\section{Acknowledgement}

The author Mrs Saeeda Nadir Ali is grateful to Higher Education Commission, Pakistan for providing Indigenous Scholarship for this research work.

\section{References}

1. Goodman LS, Hardman JG, Limbird LE, Gilman AG (2001) Goodman and Gilman's-The Pharmacological Basis of Therapeutics. (10thedn), McGraw Hill, New York, USA.

2. Sweetman SC (2007) Martindale: The Complete Drug Reference. (4thedn) Pharmaceutical Press, London.

3. Greiner-Sosanko E, Giannoutsos S, Lower DR, Virji MA, Krasowski MD (2007) Drug monitoring: simultaneous analysis of lamotrigine, oxcarbazepine 10-hydroxycarbazepine, and zonisamide by HPLC-UV and a rapid GC method using a nitrogen-phosphorus detector for levetiracetam. J Chromatographic sci 45: 616-622.

4. Theurillat R, Kuhn M, Thormann W (2002) Therapeutic drug monitoring of lamotrigine using capillary electrophoresis: Evaluation of assay performance and quality assurance over a 4-year period in the routine arena. J Chromatogr A 979: 353-368.

5. Rajendra Prasad N, Basavaiah K, Basavaiah Vinay K (2009) Determination of drug content of pharmaceuticals containing Lamotrigine by titrimetry in nonaqueous medium. Proc Indian Natl Sci Acad A Phys Sci 75: 131-136.

6. Domianguez-Renedo O, Calvo M, Arcos-Martinez MJ (2008) Determination of lamotrigine in pharmaceutical preparations by adsorptive stripping voltammetry using screen printed electrodes. Sensors 8: 4201-4212.

7. Talekar R, Dhake A, Sonaje D, Mourya V (2000) Spectrophotometric determination of lamotrigine. Indian J Pharm Sci 62: 51-52.

8. Vinay KB, Revannasiddappa HD, Rajendraprasad N, Ramesh PJ, Xavie $\mathrm{CM}$, et al. (2012) Use of two sulfonthalein dyes in the extraction-free spectrophotometric assay of tramadol in dosage forms and in spiked human urine based on ion-pair reaction. Drug Test Anal 4: 116-122.

9. Saini N, Saini K (2011) Quantitative determination of lamotrigi1ne in bulk and dosage form by UV Spectrophotometry. J Appl Pharm Sci 1: 113-116.

10. Rajendraprasad N, Basavaiah K, Vinay KB (2010) Micro and nanogram determination of lamotrigine in pharmaceuticals by visible spectrophotometry using bromophenol blue. IJCT 17: 220-228.

11. Rajendraprasad N, Basavaiah K, Vinay KB (2010) Sensitive spectrophotometric determination of lamotrigine in bulk drug and pharmaceutical formulations using bromocresol green. Ecletica Quimica 35: 55-66.

12. Vinay KB, Revanasiddappa HD, Rajendraprasad N (2009) Development and validation of spectrophotometric methods for the sensitive and selective determination of lamotrigine in pharmaceuticals using bromocresol purple. $J$ Food Drug Anal 17: 424-433.

13. Alizadeh N, Khakinahad R, Jabbari A (2008) Spectrophotometric determination of lamotrigine in pharmaceutical preparations and urine by charge-transfer complexation. Pharmazie 63: 791-795.

14. Youssef NF, Taha EA (2007) Development and validation of spectrophotometric TLC and HPLC methods for the determination of lamotrigine in presence of its impurity. Chem Pharm Bull (Tokyo) 55: 541-545.

15. Revanasiddappa HD, Deepakumari HN, Mallegowda SM (2011) Development and validation of indirect spectrophotometric methods for lamotrigine in pure and the tablet dosage forms. Analele Universitatii Bucuresti: Chimie 20: 49-55. 
Citation: Sultana N, Saeed Arayne M, Ali SN (2013) Spectrophotometric Studies of Lamotrigine Charge Transfer Complexes: Synthesis and Characterization. Pharm Anal Acta 4: 260. doi:10.4172/2153-2435.1000260

Page 6 of 6

16. Sultana N, Arayne MS, Waheed A (2011) Method Development and In vitro Interaction Studies of Verapamil in Presence, of Quinolones Using First Order Derivative UV Spectrophotometry and RP-HPLC Technique. J Chil Chem Soc 56: 848-855.

17. Siddiqui FA, Arayne MS, Sultana N, Qureshi F, Mirza AZ, et al. (2010) Spectrophotometric determination of gabapentin in pharmaceutical formulations using ninhydrin and pi-acceptors. Eur J Med Chem 45: 2761-2767.

18. Siddiqui FA, Arayne MS, Sultana N, Mirza AZ, Qureshi F, et al. (2009) Facile and Manifest Spectrophotometric Methods for the Determination of Six Quinolone Antibiotics in Pharmaceutical Formulations using Iron Salts. Med Chem Res 19: 1259-1272.

19. Arayne MS, Sultana N, Zuberi MH, Siddiqui FA (2009) Spectrophotometric Quantitation of Metformin in Bulk Drug and Pharmaceutical Formulations using Multivariate Technique. Indian J Pharm Sci 71: 331-335.

20. Arayne MS, Sultana N, Bibi Z (2009) Rapid and Specific Spectrophotometric and RP-HPLC Methods for the Determination of Ascorbic Acid in Fruit Juices and in Human Plasma. J Chem Soc Pak 31: 402-407.

21. Arayne MS, Sultana N, Hussain F (2009) Spectrophotometric Method for the Determination of Montelukast in Bulk, Pharmaceutical Formulations and Human serum. J Anal Chem 64: 690-695.
22. Tang PH, Miles MV, Glauser TA, DeGrauw T (1999) Automated microanalysis of gabapentin in human serum by high-performance liquid chromatography with fluorometric detection. J Chromatogr B Biomed Sci Appl 727: 125-129.

23. Rathore R, Lindeman SV, Kochi JK (1997) Charge-transfer probes for molecular recognition via steric hindrance in donor-acceptor pairs. J Amer Chem Soc 119: 9393-9404.

24. Refat MS, El-Hawary WF, Moussa MA (2011) IR, 1H NMR, mass, XRD and TGA/DTA investigations on the ciprofloxacin/iodine charge-transfer complex. Spectrochim Acta A Mol Biomol Spectrosc 78: 1356-1363.

25. Aloisi GG, Pignataro S (1973) Molecular complexes of substituted thiophens with $s$ and $p$ acceptors. Charge transfer spectra and ionization potentials of the donors. J Chem Soc Faraday Trans1 69: 534-539.

26. Briegleb G, Czekalla J (1960) Intensity of electron transition bands in electron donator-acceptor complexes. Z Physik Chem (Frankfurt) 24: 37-54.

27. Benesi HA, Hildebrand JH (1949) A spectrometric investigation of the interaction of iodine with aromatic hydrocarbons. J Am Chem Soc 71: 2703-2707.

28. Martin AN, Swarbrick J, Cammarata A (1969) Physical Pharmacy, (3rdedn) Lee \& Febiger, Philadelphia: 344 